\title{
Factors Affecting Seedling Emergence and Dry Matter Characteristics in Musa balbisiana Colla
}

\author{
A. B. Nwauzoma ${ }^{1,2}$ and K. Moses ${ }^{1}$ \\ ${ }^{1}$ Department of Applied \& Environmental Biology, Rivers State University of Science \& Technology, PMB 5080, \\ Port Harcourt 500001, Nigeria \\ ${ }^{2}$ Embrapa Agroenergia, PqEB-Final W3 Norte, Asa Norte, 7077091 Brasilia, DF, Brazil
}

Correspondence should be addressed to A. B. Nwauzoma; drnwabarth@yahoo.com

Received 27 June 2013; Accepted 18 July 2013

Academic Editors: F. A. Culianez-Macia and N. Rajakaruna

Copyright (c) 2013 A. B. Nwauzoma and K. Moses. This is an open access article distributed under the Creative Commons Attribution License, which permits unrestricted use, distribution, and reproduction in any medium, provided the original work is properly cited.

\begin{abstract}
The effects of storage duration $(0,2,4,6,8$, and 10 days), sterilization with sodium hypochlorite $(0,5,10,15$, and $20 \%)$, and weaning media on seedling characteristics and dry matter content in Musa balbisiana seedlings were studied. The experiment was factorial in a completely randomized design with five replicates. The result indicates that increase in $\mathrm{NaOCl}$ concentration and number of days in storage significantly $(P=0.5)$ increased the period of seedling emergence. Also, soaking in $\mathrm{NaOCl}$ for 20 min had significant effect on average seedling emergence at 15 and $20 \%$ concentrations, compared to 10 min soaking at the same concentrations. The combined effects of storage duration and sterilization resulted in a decrease in the duration of seedling emergence. Seeds previously sterilized with either water or $\mathrm{NaOCl}$ had no significant effect on seedling growth, leaf and corm dry weight, but affected almost all the dry matter traits. A mixture of poultry manure, top soil, and river sand as weaning media gave better seedling growth and increased dry matter characteristics. We conclude that $M$. balbisiana seeds require after-ripening treatment to enhance germination, sterilizing seeds with $5 \% \mathrm{NaOCl}$ for $10 \mathrm{~min}$ and air-drying under ambient condition for 2-6 days were found most appropriate, and a mixture of poultry manure, top soil, and river sand is recommended as weaning medium for growth and dry matter composition in M. balbisiana seeds.
\end{abstract}

\section{Introduction}

Bananas and plantains (Musa spp.) are giant perennial herbs that grow in the humid agroecological zones of the tropics where they are important staples and contribute significantly to the incomes of the rural dwellers that grow them in compound or home gardens [1]. Bananas and plantains are derived from intra- and interspecific crosses between the diploid wild species Musa acuminata Colla (genome A) and M. balbisiana Colla (genome B) [2]. Most cultivated Musa are triploids $(2 n=3 x=33)$ with the following genomic constitutions: dessert bananas predominantly AAA, plantains $\mathrm{AAB}$, and cooking bananas ABB [2]. The wild progenitors ( $M$. acuminata and M. balbisiana) of the edible bananas produce seeds, while most of the edible clones are seedless with a few exception such as "Pisang awak" subgroup ABB [3].

A major constraint to Musa breeding is the scarcity of healthy planting materials, due to low seed-set and viability
[4]. Intractable fertilization barriers such as moderate to high levels of female sterility and triploidy make genetic improvements of parthenocarpic Musa clones slow and technically difficult [5]. Hybrid plant production in the most common triploid clones is further complicated by low seedset and germination caused by endosperm failure [4]. Seeds are excellent dispersal units which have emerged in the course of plant evolution and are important genetic delivery systems essential for sustainable agriculture. Musa seeds are orthodox seeds; that is, the seeds can be dried to very low level moisture content (below 7\%), stored at subzero temperatures, and are employed only for propagation in breeding programs. The possibility of conserving bananas in the form of seed is envisaged for a long-term preservation of Musa sp. Under favorable environmental conditions, at least 3-6 weeks is required for the initiation of germination in soil, and germination may occur either in a flush or intermittently over a period of 3-15 weeks. Germination percentages differ 
TABLE 1: Relative proportion (\%) of weaning substrates.

\begin{tabular}{lcccc}
\hline Media & TP & PM & SD & RS \\
\hline 1 & 25 & 25 & 25 & 25 \\
2 & 33.3 & 33.3 & 0 & 33.3 \\
3 & 33.3 & 50 & 33.3 & 0 \\
4 & 50 & 50 & 0 & 0 \\
5 & 0 & 50 & 50 & 0 \\
6 & 50 & 33.3 & 16.7 & 0 \\
\hline
\end{tabular}

Spent sawdust (SD), river sand (RS), topsoil (TP), and Poultry manure (PM).

TABLE 2: Effects of sterilization $(\mathrm{NaOCl})$ and storage duration on seedling emergence in M. balbisiana.

\begin{tabular}{lcccccc}
\hline $\begin{array}{l}\text { Conc. (\%) } \\
\mathrm{NaOCl}\end{array}$ & \multicolumn{5}{c}{ Days of storage/duration of seedling } \\
& 0 & 2 & 4 & 6 & 8 & 10 \\
\hline 0 (control) & 16.7 & 17.6 & 18.8 & 20.7 & 21.6 & 22.2 \\
5 & 16.0 & 17.1 & 18.8 & 20.2 & 21.3 & 21.7 \\
10 & 18.3 & 19.8 & 21.6 & 22.3 & 25.1 & 27.3 \\
15 & 19.6 & 23.4 & 36.2 & 27.0 & 27.7 & 26.5 \\
20 & 20.2 & 22.9 & 24.2 & 27.2 & 28.8 & 28.7 \\
LSD $_{(0.05)}$ & 1.72 & 1.59 & 9.06 & 1.69 & 1.95 & 1.72 \\
\hline
\end{tabular}

markedly between harvest lots [6-8], depending on the maturity of the fruit at time of seed harvest, postharvest age of the seed, and method of storage [6,7].

Little is known about the factors that affect seed germination in $M u s a$, except that germination is extremely variable and relatively difficult to obtain under natural conditions [5]. The use of Musa seedlings as research tools and the increased emphasis on banana breeding programs require improved germination rates. Understanding the germination process will help in the conservation strategies and breeding programs [9]. Seed germination is considered as a critical phase in the reproductive cycle and is of great importance for species fitness, and variation in germination percentage has been interpreted as an adaptation to ecological conditions $[10,11]$. Several reports have indicated the limited and variable seed germination exhibited by Musa [6, 12]. The work in [5] used an optimized in vitro culture of zygotic embryos to identify factors affecting germination and seedling growth in Musa acuminata subspecies malaccensis. The work in [13] employed in vitro embryo culture technique to produce hybrid germplasm in Musa balbisiana. Therefore, the objective of this study is to evaluate the effects of seed treatment chemicals, storage conditions, and weaning media on seedling emergence, growth, and dry matter content in Musa balbisiana.

\section{Materials and Method}

2.1. Experimental Site and Collection of Samples. This work was carried out at the Rivers State University of Science and Technology, Port Harcourt, Nigeria (Department of Applied and Environmental Biology), and formerly at the
TABLE 3: Effects of soaking time and $\mathrm{NaOCl}$ concentrations on days to seedling emergence in M. balbisiana.

\begin{tabular}{lccccc}
\hline $\begin{array}{l}\text { Soaking time } \\
\text { (min) }\end{array}$ & \multicolumn{5}{c}{$\begin{array}{c}\text { NaOCl concentration/seedling } \\
\text { emergence time (days) }\end{array}$} \\
& 0 & 5 & 10 & 15 & 20 \\
\hline 10 & 17.6 & 19.3 & 20.4 & 22.6 & 23.6 \\
20 & 17.6 & 20.0 & 22.4 & 24.2 & 26.2 \\
30 & 19.3 & 21.1 & 23.8 & 23.8 & 24.9 \\
$\mathrm{LSD}_{(0.05)}$ & 1.33 & 1.23 & 1.42 & 1.31 & 1.51 \\
\hline
\end{tabular}

International Institute of Tropical Agriculture (IITA), Onne station (lat. $4^{\circ} 43 \mathrm{~N}$, long $7^{\circ} 01 \mathrm{E}$, and $10 \mathrm{~m}$ altitude above sea level). Musa balbisiana seeds were extracted from matured fruits obtained from the field genebank of IITA Onne. $M$. balbisiana Colla, a diploid ancestor of commercial parthenocarpic varieties, was used because of the availability of large quantities of seeds. The weaning substrates sawdust, river sand, topsoil, and poultry manure were obtained from Port Harcourt and Onne towns. JIK (3.5\% a.i) a Nigerian commercial product of sodium hypochlorite $(\mathrm{NaOCl})$ used for sterilization was obtained from the market. A total of 1000 freshly harvested and viable Musa balbisiana seeds were selected using floatation method. Moisture Content (MC) of the seeds was also determined [14]. The seeds were air-dried, and only properly filled ones were selected for use.

2.2. Experimental Layout and Treatments. The experiment was factorial in a completely randomised design. The factors considered were number of days in storage after extraction $(0$, $2,4,6,8$, and 10 days) and sterilization with sodium hypochlorite $(\mathrm{NaOCl}, 3.5 \%$ active ingredient), with the following concentrations $5,10,15$, and $20 \%$ and $0 \%$ as control (seeds soaked in tap water). After sterilization, seeds were washed under running tap water and air-dried under ambient room condition before planting. However, seeds with no-storage treatment $(0)$ were planted immediately, while the remaining seeds were and stored in unsealed thin cellophane from where subsequent seeds were taken and planted accordingly.

There were five replicates and 10 seeds per replicate were sown in black nursery bags measuring $21 \times 11 \mathrm{~cm}$ filled with sawdust. Medium sterilization was as described by [15] and watered with deionized water. Data on the effects of $\mathrm{NaOCl}$ concentration on days to seedling emergence after extraction was recorded. A seed was considered to have germinated when the radical had pierced through the testa up to $2 \mathrm{~mm}$ in height.

The effect of weaning media on growth parameters of $M$. balbisiana seeds was studied with six different weaning media, compounded in different ratios, namely, spent sawdust (SD), river sand (RS), topsoil (TP), and decomposed poultry manure (PM) (Table 1). Thereafter, 5-weekold seedlings (10 seedlings/weaning substrate) were planted in black nursery bags of $21 \times 11 \mathrm{~cm}$. Substrate sterilization and watering were as previously described, and data were taken at 4 and 8 weeks after transplanting on number of photosynthetically active leaves, height $(\mathrm{cm})$ of seedling from 
TABLE 4: Interaction between days after extraction (DAE) and varying concentrations of $\mathrm{NaOCl}$ on seedling emergence in $M$. balbisiana.

\begin{tabular}{|c|c|c|c|c|c|c|c|c|c|}
\hline & \multicolumn{9}{|c|}{ Days to percentage seedling emergence } \\
\hline & $10 \%$ & $20 \%$ & $30 \%$ & $40 \%$ & $50 \%$ & $60 \%$ & $70 \%$ & $80 \%$ & $90 \%$ \\
\hline \multicolumn{10}{|l|}{ DAE } \\
\hline 2 & 18.4 & 21.2 & 23.5 & 25.6 & 27.8 & 30.8 & 31.7 & 26.7 & 24.2 \\
\hline 4 & 22.3 & 24.0 & 25.3 & 27.5 & 27.4 & 29.1 & 31.4 & 34.2 & 24.2 \\
\hline 6 & 18.6 & 20.4 & 21.6 & 23.2 & 25.0 & 27.1 & 26.4 & 27.4 & 25.0 \\
\hline 8 & 19.0 & 20.9 & 22.4 & 22.9 & 24.4 & 24.9 & 24.9 & 29.9 & 23.6 \\
\hline 10 & 22.8 & 25.1 & 26.0 & 26.4 & 26.2 & 24.2 & 25.8 & 17.9 & 24.2 \\
\hline \multicolumn{10}{|l|}{$\begin{array}{l}\mathrm{NaOCl} \\
\text { Conc. (\%) }\end{array}$} \\
\hline 0 (control) & 17.4 & 19.4 & 21.3 & 21.9 & 23.0 & 23.8 & 24.6 & 24.9 & 25.1 \\
\hline 5 & 18.3 & 20.6 & 23.1 & 23.9 & 26.9 & 25.0 & 27.7 & 23.4 & 24.2 \\
\hline 10 & 20.8 & 23.0 & 23.8 & 25.6 & 25.0 & 28.0 & 27.3 & 34.6 & 24.2 \\
\hline 15 & 21.0 & 22.5 & 23.1 & 25.4 & 26.5 & 27.1 & 29.5 & 23.9 & 14.2 \\
\hline 20 & 23.7 & 26.0 & 27.4 & 28.7 & 29.4 & 32.1 & 31.1 & 29.4 & 33.5 \\
\hline $\operatorname{LSD}_{(0.05)}$ & 1.25 & 1.38 & 1.32 & 1.28 & 1.41 & 1.52 & 1.45 & 1.48 & NS \\
\hline
\end{tabular}

DAE: Days after extraction.

the base of the pseudostem ("soil level") to the level of the last foliage, excluding the cigar leaves; plant girth/circumference $(\mathrm{cm})$ taken from the base of the pseudostem above ground level and leaf area [16]. Leaf area $=(L \times W) 0.8$, where $L=$ length of leaf and $W=$ width of leaf.

Destructive sampling was done at the end of 8 weeks on five randomly selected seedlings from each weaning medium, and data on the number of roots, length of longest roots $(\mathrm{cm})$, and fresh weight (g) of corms, roots, leaves, and pseudostem, as well as their respective dry weights at $70^{\circ} \mathrm{C}$, were recorded. Data were analyzed with GENSTAT Discovery Edition 1 [17] in a factorial completely randomized design. The least significant difference (LSD) at the 5\% probability level was used to separate the means and detect the effects of storage, sterilization, weaning media, and interaction between storage and concentrations of sterilization medium on M. balbisiana seeds.

\section{Results}

Sterilization with sodium hypochlorite $(\mathrm{NaOCl})$ at higher concentration significantly $(P=0.05)$ influenced the number of days to seedling emergence in $M$. balbisiana. The shortest duration in seedling emergence was observed in 5\% concentration $\mathrm{NaOCl}$ which was not significantly different from the control (Table 2). There was no significant difference between seeds sterilized with 15 and $20 \% \mathrm{NaOCl}$, except in day 4 where seeds with $15 \% \mathrm{NaOCl}$ sterilization took longer days ( 36.2 days) to emerge compared to 24.2 days in $20 \% \mathrm{NaOCl}$ (Table 2). However, significant differences were observed between 20 and $10 \%$ concentration in all of the treatments. Thus, increase in both $\mathrm{NaOCl}$ concentration used in seed sterilization and number of days in storage resulted in an increase in the number of days to seedling emergence.

Soaking in $\mathrm{NaOCl}$ for 20 min had significant effect on average seedling emergence in M. balbisiana at 15 and 20\% concentrations, compared to $10 \mathrm{~min}$ soaking at the same concentrations (Table 3). Also, soaking for $30 \mathrm{~min}$ at $20 \%$ $\mathrm{NaOCl}$ resulted in longer days to seedling emergence in $M$. balbisiana at various concentrations (Table 3).

There was a significant interaction effect between days after extraction and varying concentrations of $\mathrm{NaOCl}$ on seedling emergence, except at $90 \%$ emergence (Table 4). Seeds soaked in water $(0 \%)$, which was the control, emerged earlier than other treatments, except in $90 \%$ germination, while seeds sterilized with $20 \% \mathrm{NaOCl}$ took longer days to emerge. At two, 6, and $8 \mathrm{DAE}$ had the shortest period to emergence at $10 \%, 20 \%$, and $30 \%$, respectively, while $8 \mathrm{DAE}$ had the shortest seedling emergence period in $40-70 \%$. At $10 \%$ emergence, 2 and 10 DAE had the shortest (18.4) and longest (22.8) days to emergence, while at $30 \%$ the maximum (26.0) and minimum (21.6) days to emergence were at 10 and 6 DAE. At 70\% emergence, 8 and 2 DAE had the shortest (24.9) and longest (31.7) days to emergence. It was further observed that 8 and 6 DAE had the longest (25.0) days, while an equal number of days were noted for 2,4 , and 10 DAE to seedling emergence, which was the shortest. Thus, increase in days after extraction causes decrease in the number of days to emergence (Table 4).

Seeds previously sterilized with either water or $\mathrm{NaOCl}$ had no significant effect on number of leaves, seedling height, leaf and corm dry weight, and corm dry matter (Table 5). However, significant effects were observed on total dry matter, stem dry weight, and almost all the dry matter traits (Table 5). Although seeds soaked in water resulted in taller seedlings, seeds sterilized with sodium hypochlorite had higher percentage root and leaf dry matter.

Table 6 shows the effect of weaning media on seedling height, number of leaves, and dry matter yield and distribution in M. balbisiana seedlings. Seedlings grown in a mixture of poultry manure, top soil, and river sand (PM/TP/RS; weaning media 2) as well as those on poultry 
TABLE 5: Effects of previous seed treatments on growth, dry matter yield, and distribution in M. balbisiana seedlings.

\begin{tabular}{lccccccccccc}
\hline \multirow{2}{*}{ Previous seed treatment } & \multirow{2}{*}{$\mathrm{Ht}(\mathrm{cm})$} & \multirow{2}{*}{$\mathrm{NL}$} & \multicolumn{4}{c}{ Dry weight (g) } & \multicolumn{4}{c}{ Dry matter (\%) } \\
& & & TDW & Root & Stem & Leaf & Corm & Root & Stem & Leaf & Corm \\
\hline Water & 48.6 & 7.7 & 22.1 & 2.04 & 9.43 & 9.22 & 1.44 & 10.3 & 37.8 & 45.6 & 6.39 \\
$\mathrm{NaOCl}$ & 47.8 & 7.5 & 16.1 & 2.12 & 4.31 & 8.62 & 1.03 & 14.6 & 26.7 & 52.4 & 6.37 \\
$\mathrm{LSD}_{(0.05)}$ & $\mathrm{NS}$ & $\mathrm{NS}$ & 4.40 & 2.93 & 2.93 & $\mathrm{NS}$ & $\mathrm{NS}$ & 2.91 & 4.7 & 4.6 & $\mathrm{NS}$ \\
\hline
\end{tabular}

Ht: height of seedling, NL: number of leaves, and TDW: total dry weight.

TABLE 6: Effect of weaning media on growth, dry matter yield, and distribution in M. balbisiana seedlings.

\begin{tabular}{|c|c|c|c|c|c|c|c|c|c|c|c|}
\hline \multirow{2}{*}{ Weaning media } & \multirow{2}{*}{$\mathrm{Ht}(\mathrm{cm})$} & \multirow{2}{*}{ NL } & \multicolumn{5}{|c|}{ Dry weight $(\mathrm{g})$} & \multicolumn{4}{|c|}{ Dry matter (\%) } \\
\hline & & & TDW & Root & Stem & Leaf & Corm & Root & Stem & Leaf & Corm \\
\hline 1 & 51.4 & 7.0 & 25.53 & 2.85 & 11.66 & 9.76 & 1.25 & 12.4 & 39.73 & 42.31 & 5.53 \\
\hline 2 & 56.2 & 7.6 & 25.20 & 2.42 & 9.10 & 11.42 & 2.26 & 10.1 & 32.15 & 49.58 & 8.14 \\
\hline 3 & 45.0 & 7.1 & 12.08 & 1.58 & 4.42 & 5.41 & 0.67 & 15.0 & 33.10 & 46.12 & 5.82 \\
\hline 4 & 52.2 & 8.0 & 20.64 & 2.57 & 5.63 & 11.05 & 1.39 & 12.4 & 28.00 & 53.10 & 6.51 \\
\hline 5 & 34.6 & 8.2 & 8.06 & 1.28 & 2.28 & 3.99 & 0.52 & 17.1 & 27.47 & 48.94 & 6.54 \\
\hline 6 & 49.8 & 7.5 & 23.8 & 1.78 & 8.13 & 11.86 & 1.31 & 7.62 & 32.91 & 53.77 & 5.69 \\
\hline $\operatorname{LSD}_{(0.05)}$ & 6.42 & 0.8 & 7.62 & 0.76 & 5.06 & 2.97 & 1.01 & 5.04 & 8.14 & 7.88 & 2.47 \\
\hline
\end{tabular}

Weaning media: 1: PM/TP/SD/RS; 2: PM/TP/RS; 3: PM/TP/SD; 4: PM/TP; 5: PM/SD; 6: PM/TP/SD; PM: poultry manure; TP: top soil; SD: sawdust and RS: river sand; Ht: height of seedling; NL: number of leaves; TDW: total dry weight.

manure/topsoil/sawdust/river sand (PM/TP/SD/RS; weaning media 1) and a mixture of poultry manure/top soil (PM/TP; weaning media 6) were significantly taller, compared to other treatments (Table 6). At least seven leaves were produced in each weaning medium, although significantly higher numbers were observed in weaning media 4 and 5. There were differences in dry weight traits; for instance, total dry weight was lowest in weaning media $5(8.06 \mathrm{~g})$ and weaning media $4(20.64 \mathrm{~g})$. The other weaning media had total dry weight (TDW) ranging from $23.8 \mathrm{~g}$ to $25.5 \mathrm{~g}$. Root dry weight was higher in weaning media 1,2 , and 4 than in 3, 5, and 6. Stem dry weight was significantly different in weaning media 1,2 , and 6 with 11.66, 9.10, and $8.13 \mathrm{~g}$, respectively. The least values for this trait were observed in weaning media $5(2.28 \mathrm{~g}), 3$ (4.42 g), and 4 (4.53g). Higher leaf dry weight was obtained in weaning media $1,2,4$, and 6 , while the same for corm was highest in weaning medium 2 (2.26 g), followed by media 4 , 6, and 1 , that is, $1.39 \mathrm{~g}, 1.31 \mathrm{~g}$, and 1.25 in that order. Percentage dry matter in root was higher in weaning media 5 and 3 and the least in $6(7.62 \%)$. In stem, percentage of dry matter was highest in weaning medium 1 (39.73) and lowest in 5 (27.47). Significantly higher, percentage of leaf dry matter was produced in weaning medium 6 with 53.77, compared to weaning medium 1 which had 42.31. Similar observations were made in \% corm dry matter.

\section{Discussion}

There are reports that storage duration $[9,18-20]$, soaking in water $[6,21,22]$, and sterilization with sodium hypochlorite [20] affect seed germination characteristics in plants. The present work confirms that increase in $\mathrm{NaOCl}$ concentration and number of days in storage resulted in an increase in the number of days to seedling emergence in Musa balbisiana.
Similar results were obtained by [9] on germination and seedling characteristics of Periploca angustifolia Labill after long duration in storage. This is because as seeds get older the membrane system gradually becomes permeable allowing many electrolytes to flow out of cells leading to loss of vigor in such seeds. Similar effects were also observed when seeds were soaked in higher concentrations of $\mathrm{NaOCl}$ for a long time. Though sterilization with $\mathrm{NaOCl}$ is reported to reduce competition with pathogens which could impede the rate of growth and development of seedlings, [20], also it prolongs seedling emergence. It could be that the seeds may have to be resterilized after 10 days to reduce the time for seedling emergence. Soaking in water had better seedling emergence than $\mathrm{NaOCl}$. Our findings further show that delayed planting for 10 days after seed extraction reduced seedling emergence which could be attributed to loss of seed viability as a result of loss in moisture. It was evident from the study that soaking duration influenced earliness to emergence and the total number of seedlings that emerged, while sterilization significantly affected the quality of seedlings produced. Seedlings arising from previously sterilized seeds had less total dry weight accumulation than water soaked seeds. This could be as a result of long duration of soaking seeds in $\mathrm{NaOCl}$ concentration. According to [23], the percentage germination in Musa balbisiana is highly variable depending on factors such as fruit maturity at seed harvest, the postharvest age of the seed, and the method of storage. The work in [21] reported that embryo germination was achieved in Musa balbisiana seeds after soaking in water for five days, prior to embryo excision. Similarly, Simmonds [6] and [23] also reported that the soaking of Musa seeds before sowing was either deleterious or ineffective to germination.

A mixture of poultry manure, top soil, and river sand as a weaning medium resulted in better seedling growth 
and dry matter characteristics, which is supposed to be a reflection of the chemical properties of the medium. It should be noted that 5 out of the 6 weaning media formulations had the same proportion of poultry manure as nutrient source. Lower bulk density enhances better root substrate relation [22], provided such media have the ability to hold the plant firmly in place and at the same time have adequate drainage and aeration [24]. A combination of poultry manure, top soil, sawdust, and river sand (PM/TP/SD/RS) with poultry manure, top soil, and river sand (PM/TP/RS) had higher bulk density and were more aggregated than sawdust and poultry manure (SD/PM), thus having relatively greater pore spaces for proper aeration. Media compaction and in situ media decomposition could cause an undesirable decrease in drainage and aeration leading to impediment of root growth. The decomposition of SD causes a depletion of available nitrogen within the potting mixture [25]. Thus, poor plant performance of SD/PM in the traits studied might be due to nutrient deficiency, especially nitrogen immobilization.

In conclusion, $M$. balbisiana seed needs after-ripening treatment to enhance seedling germination. Also, sterilizing $M$. balbisiana seeds with $5 \%$ dilution of sodium hypochlorite $(\mathrm{NaOCl})$ at $10 \mathrm{~min}$ duration and air-drying under ambient tropical room condition for 2-6 days were found most appropriate. Finally, a mixture of poultry manure, top soil, and river sand is most appropriate as weaning media for growth and dry matter composition in M. balbisiana.

\section{References}

[1] F. I. Nweke, J. E. Njoku, and G. F. Wilson, "Productivity and limitations of plantain (Musa spp. Cv. AAB) production in compound gardens in southeastern Nigeria," Fruits, vol. 43, pp. 161-166, 1998.

[2] N. W. Simmonds, "Bananas," in Evolution of Crop Plants, J. Smart and N. W. Simmonds, Eds., pp. 370-374, John Wiley \& Sons, New York, NY, USA, 1995.

[3] N. W. Simmonds, Bananas, Longmans, Green and Co., London, UK, 1966.

[4] K. J. Shepherd, L. L. Dantas, and B. Alves, "Banana breeding in Brazil," in Banana and Plantain Breeding Strategies, G. J. Persley and E. A. De Langhe, Eds., pp. 78-83, ACIAR, Canberra, Australia, 1987.

[5] M. J. Asif, C. Mak, and R. Y. Othman, "In vitro zygotic embryo culture of wild Musa acuminata ssp. malaccensis and factors affecting germination and seedling growth," Plant Cell, Tissue and Organ Culture, vol. 67, no. 3, pp. 267-270, 2001.

[6] N. W. Simmonds, "The germination of banana seeds," Journal of Tropical Agriculture, vol. 29, pp. 35-49, 1952.

[7] N. W. Simmonds, "Experiments on the germination of banana seeds," Tropical Agriculture, vol. 36, pp. 259-273, 1959.

[8] R. H. Stover, "A Rapid and simple pathogenicity test for detecting virulent clones of Fusarium oxysporum $f$. cubense using seedlings of Musa balbisiana," Nature, vol. 184, no. 4698, pp. 1591-1592, 1959.

[9] R. Abdellaoui, A. Souid, D. Zayoud, and M. Neffati, "Effects of natural long storage duration on seed germination characteristics of Periploca angustifolia Labill," African Journal of Biotechnology, vol. 12, no. 15, pp. 1760-1768, 2013.
[10] L. Navarro and J. Guitián, "Seed germination and seedling survival of two threatened endemic species of the northwest Iberian peninsula," Biological Conservation, vol. 109, no. 3, pp. 313-320, 2003.

[11] L. Rajjou and I. Debeaujon, "Seed longevity: survival and maintenance of high germination ability of dry seeds," Comptes Rendus, vol. 331, no. 10, pp. 796-805, 2008.

[12] N. Pancholi, A. Wetten, and P. D. Caligari, "Germination of Musa velutina seeds: comparison of in vivo and in vitro system," In Vitro Cellular and Developmental Biology, vol. 31, no. 3, pp. 127-130, 1995.

[13] K. Z. Ahmed, S. Remy, L. Sági, and R. Swennen, Germination of Musa balbisiana seeds and embryos.XVII Reunioa Internacional da Associacao para Cooperacao nas Pesquisas sobre Banana no Caribe e na America Tropical 15 a 20 de Outubro de 2006-Joinville-Santa Catarina, Brasil, 2006.

[14] ISTA, The International Seed Testing Association, Basserdorf, Switzerland, 2003.

[15] C. U. Agbo and C. M. Omaliko, "Initiation and growth of shoots of Gongronema latifolia Benth stem cuttings in different rooting media," African Journal of Biotechnology, vol. 5, no. 5, pp. 425428, 2006.

[16] J. C. Obiefuna and T. O. C. Ndubizu, "Estimating leaf area of plantain," Scientia Horticulturae, vol. 11, no. 1, pp. 31-36, 1979.

[17] GENSTAT, GENSTAT 5. 0 Release 4. 23DE, Lawes Agricultural Trust, Rothamsted Experimental Station, 1st edition, 2003.

[18] M. B. McDonald, "Seed deterioration: physiology, repair and assessment," Seed Science and Technology, vol. 27, no. 1, pp. 177237, 1999.

[19] C. C. Hsu, C. L. Chen, J. J. Chen, and J. M. Sung, "Accelerated aging-enhanced lipid peroxidation in bitter gourd seeds and effects of priming and hot water soaking treatments," Scientia Horticulturae, vol. 98, no. 3, pp. 201-212, 2003.

[20] K. P. Baiyeri and B. N. Mbah, "Surface sterilization and duration of seed storage influenced emergence and seedling quality of African breadfruit (Treculia africana Decne)," African Journal of Biotechnology, vol. 5, no. 15, pp. 1393-1396, 2006.

[21] J. C. Afele and E. de Langhe, "Increasing in vitro germination of Musa balbisiana seed," Plant Cell, Tissue and Organ Culture, vol. 27, no. 1, pp. 33-36, 1991.

[22] V. I. Ayodele, "Substrates for production of ornamental in Nigeria," in Proceeding 15th HORTSON Conference, NIHORT Ago Iwoye, April 1997.

[23] O. Stotzky, C. A. Cox, and R. D. Goose, "Seed germination studies in Musa. I. Scarification and aseptic germination of Musa balbisiana," American Journal of Botany, vol. 49, pp. 515520, 1962.

[24] A. C. Bunt, Modern Potting Composts, Pennsylvania State University Press, 1976.

[25] L. W. Woodstock, "Seed Imbibition: a critical period for successful germination," Journal of Seed Technology, vol. 12, pp. 1-15, 1988. 

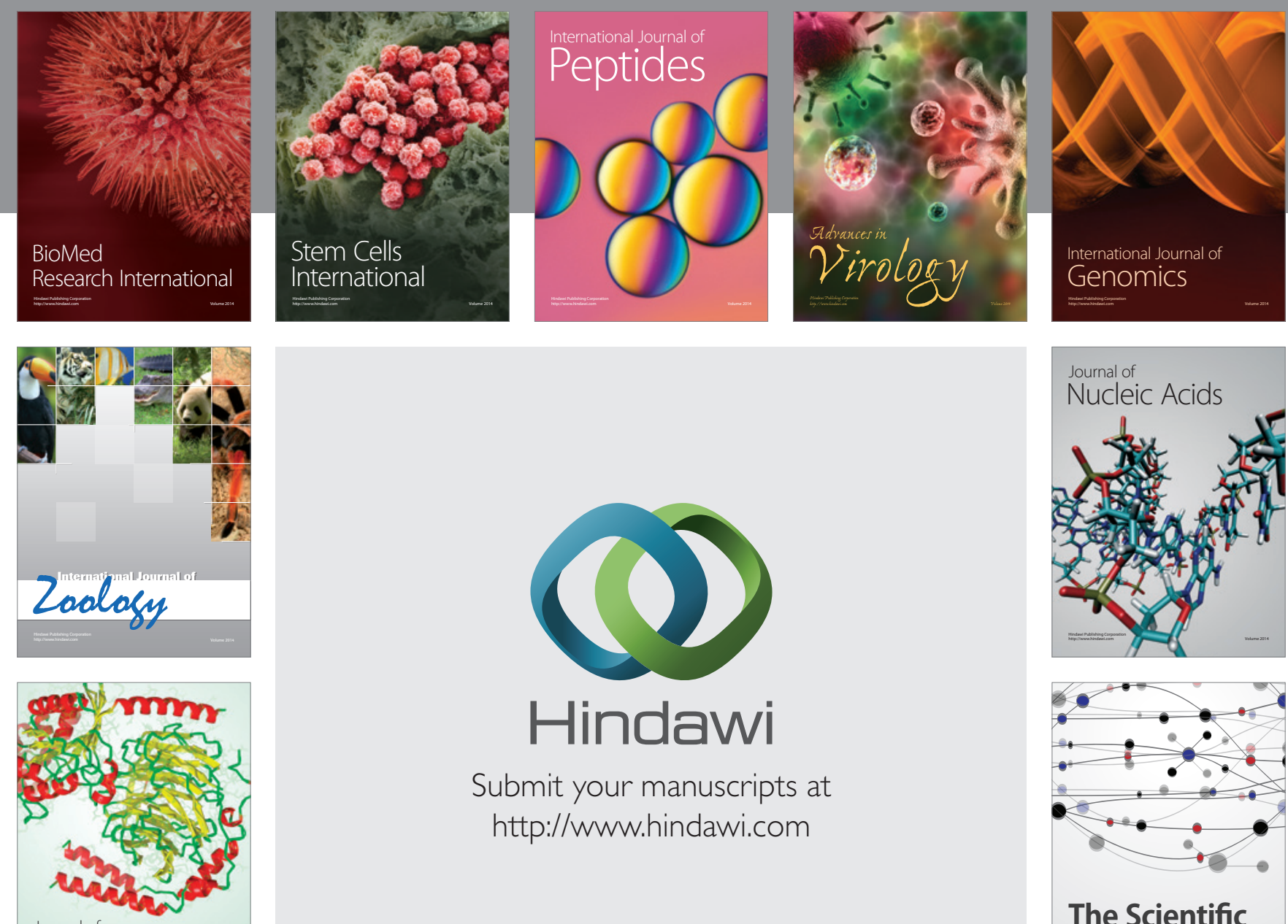

Submit your manuscripts at

http://www.hindawi.com

Journal of
Signal Transduction
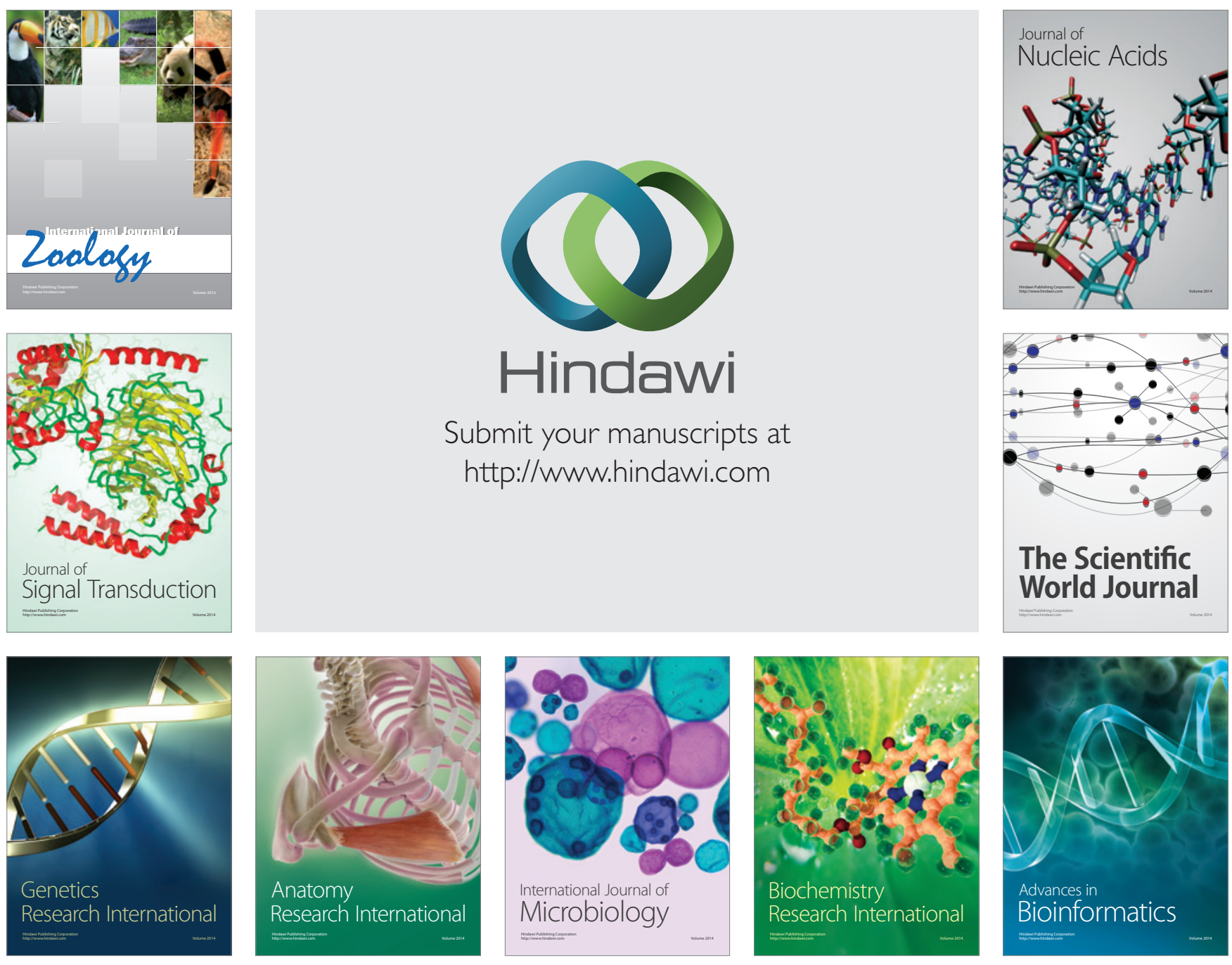

The Scientific World Journal
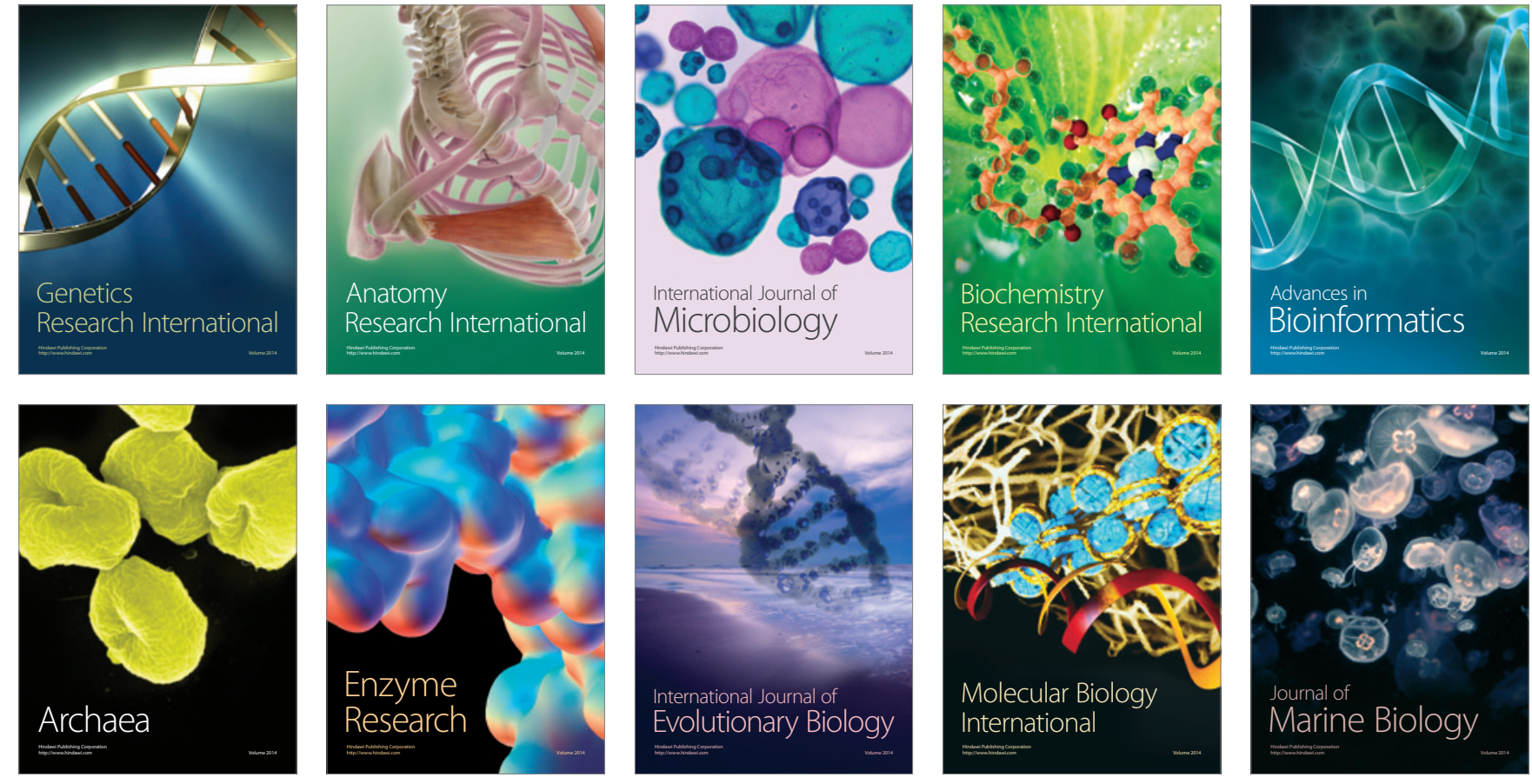